\title{
IJCIT
}

(Indonesian Journal on Computer and Information Technology)

Journal Homepage: http://ejournal.bsi.ac.id/ejurnal/index.php/ijcit

\section{Perancangan Dan Implementasi Smart Library Untuk Meningkatkan Operasional Perpustakaan (Studi Kasus : SMP Negeri 2 Cisaat Sukabumi)}

\author{
Indri Andriyani ${ }^{1}$, Cecep Kurnia Sastradipraja², Sudin Saepudin ${ }^{3}$ \\ 1,2,3 Sistem Informasi, Universitas Nusa Putra \\ Sukabumi, Indonesia

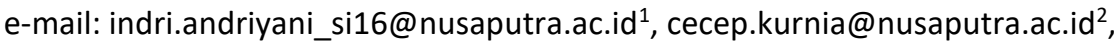 \\ sudin.saepudin@nusaputra.ac.id ${ }^{3}$
}

\begin{abstract}
A B S T R A K
Perpustakaan sebagai salah satu media pembelajaran bagi para siswa dalam mencari sumber referensi belajar dan berperan penting dalam menunjang proses pendidikan. Pada SMP Negeri 2 Cisaat Sukabumi perpustakan adalah salah satu sarana bagi siswa untuk mencari referensi pelajaran. Namun pada sistem yang sedang berjalan saat ini, perpustakaan masih menggunakan sistem manual yaitu dengan pencatatan pembukuan, kelola anggota, dan notifikasi peminjaman. Proses manual tersebut dinilai kurang efisien dan memakan banyak waktu, serta dokumen yang dapat rusak atau hilang disebabkan kejadian tertentu. Oleh karena itu dibutuhkan sistem informasi yang dapat mengelola manajemen perpustakaan dengan lebih efektif dan efisien dengan menggunakan smart library berbasis web. Model prototipe adalah salah satu Model System Development Life Cycle (SDLC) yang dapat membantu proses pembangunan Smart Library berbasis web. Sehingga dapat membantu manajemen perpustakaan lebih terstruktur dan dengan proses yang cepat, efektif, dan efisien. Hasil dari kuisioner pengujian beta rata-rata menunjukan $80 \%$ menjawab setuju pada aplikasi smart library yang dibuat.
\end{abstract}

Katakunci: Perpustakaan, Smart Library, Prototipe

\begin{abstract}
A B S TR A CTS
Library as one of the learning media for students in finding sources of learning references and plays an important role in supporting the educational process. At SMP Negeri 2 Cisaat Sukabumi library is one of the means for students to find reference lessons. But in the current system, the library still uses a manual system, namely by recording books, managing members, and borrowing notifications. The manual process is considered inefficient and time-consuming, as well as documents that can be damaged or lost due to certain events. Therefore we need an information system that can manage library management more effectively and efficiently by using web-based Smart Library. Prototype Model is one of the System Development Live Cycle Model (SDLC) that can help the process of building a web-based Smart Library. So that it can help library management be more structured and with a fast, effective, and efficient process. The results of the beta test questionnaire on average showed $80 \%$ answered agreed on the smart library application made.
\end{abstract}

Keywords: Library, Smart Library, Prototype 


\section{PENDAHULUAN}

Perpustakaan merupakan tempat penyimpanan, pengolahan, dan pencarian informasi yang dapat berbentuk buku, jurnal, referensi, dan bahan pustaka tercetak lainnya maupun bahan bacaan dalam bentuk elektronik (electronic book, electronic journal, dan bahan bacaan bentuk elektronik lainnya) Di dalam perpustakaan tersebut ada organisasi dan sistem yang mengatur perjalanan bahan pustaka atau informasi mulai dari pengadaan, peminjaman hingga pelayanan dan penyajian kepada pengguna perpustakaan (Saleh and Komalasari 2014). SMP Negeri 2 Cisaat Sukabumi adalah salah satu sekolah yang mempunyai fasilitas perpustakaan, namun dalam pelaksanaannya masih bersifat manual yaitu transaksi peminjaman dan pencarian referensi buku masih dalam bentuk komputerisasi Microsoft excel. Selain itu, proses transaksi yang dilakukan masih menggunakan penginputan manual sehingga membutuhkan banyak waktu untuk proses transaksi. Permasalahan selanjutnya terdapat pada bagian pengingat kepada siswa peminjam yang sering lupa untuk mengembalikan buku kepada perpustakaan, sehingga banyak buku yang hilang karena kurangnya monitoring pada sistem perpustakaan. Seperti dalam penelitian sebelumnya sistem informasi sangat penting untuk diterapkan pada operasional perpustakaan, karena dapat membantu dan menambah fasilitas perpustakaan agar lebih efektif dan efesien (Titan, Luhukay, and Kurniawan 2014). Kemudian sistem informasi berbasis web akan sangat fleksibel untuk diterapkan ke dalam sistem dan pembangunan sistem yang sederhana namun mudah untuk digunakan oleh user (Industri et al. 2015). Melihat dari permasalahan dan penelitian sebelumnya maka perlu adanya smart library untuk menunjang operasional perpustakaan dengan menggunakan metode prototype dan berbasis website. Perbedaan dari penelitian sebelumnya, Smart Library ini menggunakan API WhatsApp sebagai notifikasi kepada siswa untuk reminder dalam pengembalian buku dan jadwal peminjaman kembali, hal ini karena dukungan teknologi WhatsApp yang merupakan platform yang menawarkan layanan dalam mengelola dan mengatur semua data dan informasi dengan memberikan kenyamanan untuk menggunakan dan mengakses layanan di mana saja dan kapan saja (Westerkamp, Gondor, and Kupper 2019). Selain itu terdapat juga QRCode untuk scan input buku dan peminjaman buku, sehinga mengatasi biaya pembelian alat scanner. Adapun kelebihan teknologi QRCode dapat memberikan kemudahan dalam interaksi baik penggunaan seluler atau website dengan menghilangkan pengetikan atau input data secara manual (Alnajjar et al. 2016). Tujuan dari penelitian ini untuk merancang dan mengimplementasikan smart library pada perpustakaan SMPN 2 Cisaat Sukabumi.

\section{METODE PENELITIAN}

Metode Penelitian yang dilakukan adalah metode kualitatif dengan mengumpulkan data atas kebutuhan sistem dengan cara studi pustaka, observasi, dan wawancara pada narasumber di SMPN 2 Cisaat Sukabumi. Berikut merupakan skema tahapan penelitian yang dilakukan.



Gambar 1. Skema Tahapan Penelitian

Dalam memperbaiki kekurangan pada sistem yang berjalan dibutuhkan model analisis dan perancangan sistem. Pada penelitian ini model yang akan digunakan adalah model UML (Unfied Modeling Language), karena UML adalah salah satu alat yang dapat digunakan dalam bahasa pemrograman berorientasi objek, merupakan sintaks umum untuk membuat model logika suatu sistem dan digunakan untuk mendeskripsikan sistem sehingga dapat dipahami. Saat ini UML mulai menjadi standar 
kedepan untuk dunia industri (Braude 2017). UML yang digunakan menggunakan empat diagram yang terdiri dari use case diagram, activity diagram, sequence diagram, dan class diagram. Model UML mampu menggambarkan dengan baik sistem yang sedang berjalan, maupun sistem yang diusulkan.

Pada pengembangan sistem smart library menggunakan model prototype. Model prototype mempunyai kelebihan untuk bisa langsung berinteraksi dengan user secara fleksibel (Rosi Subhiyakto and Wahyu Utomo 2017). Karena dapat diperbaiki kapan pun ketika sistem tidak sesuai dengan sistem yang berjalan, untuk itu dibuat sistem usulan untuk memperbaiki dan menambahkan fitur pada sistem berjalan.

Implementasi sistem terdiri dari aplikatif hardware, website, serta perancangan database. Untuk pengujian sistem dilakukan menggunakan Blackbox testing dan Beta testing menggunakan skala likert pada kuisioner yang dibagikan kepada user. Skala likert secara umum digunakan untuk menghitung keberhasilan pada sistem berdasarka kuisoner, seperti pada penelitian sebelumnya Sistem Informasi Angket menggunakan skala likert (Julika and Setiyawati 2019).

\section{HASIL DAN PEMBAHASAN}

Pada hasil dan pembahasan berisi perancangan model sistem, implementasi aplikasi, pengunaan WhatsApp API dan Qrcode, dan pengujian sistem smart library.

\subsection{Analisis Sistem}

Menurut (Dalpiaz and Brinkkemper 2018) analisis kebutuhan sistem memiliki pengertian bahwa keseluruhan sistem informasi menjadi bagian dari suatu komponen yang mempunyai tujuan untuk mengidentifikasi dan mengevaluasi macam-macam masalah atau kendala yang akan datang dan masuk ke sistem sehingga di masa yang akan datang dapat diatasi, ditingkatkan dan juga dikembangkan. Tujuan dari analisis adalah untuk memahami kebutuhan sistem yang akan dibangun dengan mengembangkan sistem yang mewakili kebutuhan, baik untuk kebutuhan sistem maupun pengguna. Berdasarkan hasil penelitian yang dilakukan bahwa prosedural sistem yang sedang berjalan dapat dimodelkan dengan diagram use case pada gambar 2 .



Gambar 2. Sistem Perpustakaan Berjalan

Analisa sistem usulan merupakan gambaran lengkap dari sistem yang akan diusulkan. Model diagram use case sistem usulan dapat dilihat pada gambar 3 .



Gambar 3. Sistem Perpustakan Usulan

Kemudian dalam implementasi sistem smart library dapat digambarkan flowchart dari sistem yang dibangun, kelebihan dari sistem informasi perpustakaan ini dibandingakan dengan penelitian sebelumnya yaitu telah terintegrasi API WhatsApp untuk mengirimkan pesan notifikasi gateway (Rachman et al. 2017), dan telah dilengkapi QRcode sebagai scanning peminjaman buku. Flowchart smart library dapat dilihat pada gambar 4 . 


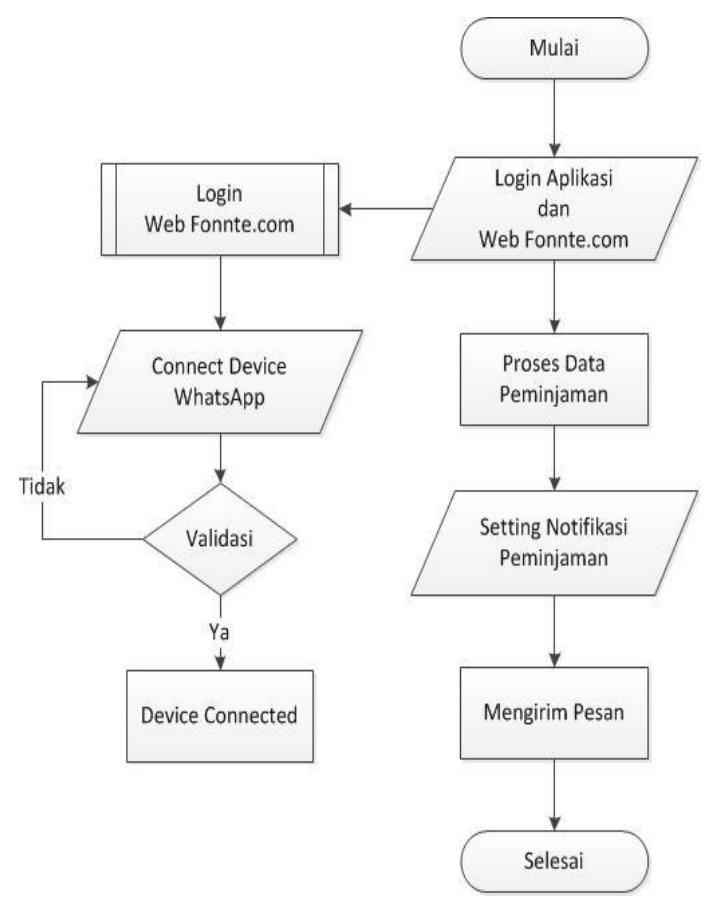

Gambar 4. Flowchart Smart Library

Kemudian dalam perancangan database diperlihatkan dalam bentuk class diagram sebagai relation antar tabel, seperti pada gambar 5.



Gambar 5. Class Diagram Smart Library

\subsection{Implementasi Aplikasi}

Implementasi pada aplikasi smart library perpustakan SMP Negeri 2 Cisaat dengan memanfatkan whatsaap API sebagai perantara notifikasi kepada siswa atau pengunjung perpustakaan. Aplikasi smart library pada perpustakaan SMP Negeri 2 Cisaat dapat digunakan apabila telah melakukan proses instalasi sistem. Implementasi aplikasi ini dapat dilihat pada implementasi antarmuka sebagai hasil dari implementasi perancangan sistem.

\subsubsection{Halaman Login}

Halam Login menampilkan pengisian username dan password. Halaman ini untuk login admin perpustakaan.



Gambar 6. Halaman Login

\subsubsection{Halaman Utama Sistem}

Halaman utama sistem berisi daftar kategori buku dan daftar buku yang tersedia di perpustakaan.



Gambar 7. Halaman Utama Sistem

\subsubsection{Data Buku}

Halaman ini berisi data buku yang tersedia dan telah diinputkan ke dalam sistem, dalam data buku admin perpustakaan dapat menambah, mengedit, menghapus, dan mencari data. 




Gambar 8. Halaman Data Buku

\subsubsection{Halaman Data Kategori}

Halaman data kategori berisi data kategori buku untuk mengklasifikasi jenis buku berdasarkan kategori. Dari mulai buku mata pelajaran, novel, hiburan dan lainnya. Admin perpustakaan dapat menambah, mengedit, menghapus, dan mencari data pada sistem.



Gambar 9. Halaman Data Kategori

\subsubsection{Halaman Data Pengarang}

Halaman ini berisi data pengarang dari buku. Admin perpustakaan dapat menambah, mengedit, menghapus, dan mencari data pengarang.



Gambar 10. Halaman Data Kategori

\subsubsection{Halaman Data Rak}

Halaman data rak berisi data rak buku atau lokasi penyimpanan buku pada perpustakaan. Admin perpustakaan dapat menambah, mengedit, menghapus dan mencari data rak buku.



Gambar 11. Halaman Data Rak

\subsubsection{Halaman Data Peminjaman}

Halaman ini berisi data peminjaman buku oleh siswa maupun umum. Admin perpustakaan dapat menambah, mengedit, menghapus, dan mencari data peminjaman.



Gambar 12. Halaman Data Peminjaman

\subsubsection{Halaman Setting Notifikasi}

Halaman ini berisi setting notifikasi pesan kepada peminjam buku, daftar notifikasi akan muncul ketika ada peminjam buku baru, masing masing peminjam buku dapat diset pesan untuk pengembalian buku atau pemberitahuan lainnya. Admin perpustakan dapat mengirimkan notifikasi, mengatur isi pesan WhatsApp.



Gambar 13. Halaman Setting Notifikasi



Gambar 14. Halaman Setting Pesan Notifikasi 


\subsubsection{Halaman Setting Notifikasi}

Halaman ini berisi pengaturan profil pada sistem. Admin perpustakaan dapat mengganti Logo, Nama Sistem, Alamat dan Footer. Kemudian dapat mengganti tema warna pada sistem.

\subsection{Implementasi WhatsApp API}

WhatsApp API pada smart library SMPN 2 Cisaat menggunakan aplikasi pihak ke 3 yaitu Fonnte.com yang menyediakan API WhatsApp, digunakan untuk mengirim pesan kepada siswa yang meminjam buku sehingga mendapatkan notifikasi dari sistem. Berikut ini beberapa tahapan implementasi WhatsApp API yang akan diterapkan kedalam sistem.

Agar API WhatsApp dapat digunakan, maka perlu diadakannya koneksi terlebih dahulu dengan server Fonnte.com, dengan cara scan barcode agar terhubung ke dalam server.



Gambar 17. Halaman Setting Website



Gambar 15. Koneksi WhatsApp API

Agar API WhatsApp dapat berjalan pada smart library, maka harus diimplementasikan code API kedalam sistem. Sehingga dapat mengirimkan pesan melalui aplikasi Smart Library.



Gambar 16. Code WhatsApp API

\subsection{Pengujian Sistem}

Sebelum program diimplementasikan, program harus terbebas dari kesalahan. Untuk itu, program harus diuji terlebih dahulu untuk mengetahui kesalahan yang mungkin terjadi. Pengujian sistem dilakukan dengan teknik blackbox testing, dimana untuk pengujian program langsung melihat pada aplikasi tanpa perlu mengetahui struktur program. Pengujian ini dilakukan untuk melihat apakah suatu program sudah terpenuhi atau belum (Satoto et al. 2016). Pada tahap pengujian sistem, Pembangunan aplikasi smart library dilakukan pengujian sistem, diantaranya terdiri dari pengujian blackbox dan pengujian beta. Pengujian ini dilakukan untuk mengetahui apakah aplikasi smart library befungsi dengan baik dan aplikasi berjalan sesuai yang diinginkan pengguna.

Hasil pengujian blackbox dilakukan oleh penguji sistem, hasil pengujian mempunyai dua kategori yaitu gagal dan berhasil. Masing masing komponen uji diberikan hasil pengujian seperti tampak pada tabel 1.

\subsection{Pengujian Beta}

Pengujian beta merupakan pengujian yang akan dilakukan oleh pengguna smart library dengan objektif. Penelitian ini dilakukan di SMPN 2 Cisaat dengan menggunakan kuisioner. Hal tersebut dilakukan untuk mengukur sejauh mana website yang dibangun dapat membantu menyelesaikan masalah pada perpustakaan SMPN 2 Cisaat. Pengujian Beta menggunakan perhitungan skala likert terlihat pada table 2 .

Perhitungan dilakukan berdasarkan pertanyaan kuisioner yang dapat dilihat pada tabel 3.

Perhitungan kuisioner dilakukan satu persatu pertanyaan. masing-masing dihitung dan mempunyai hasil yang akan dikalkulasikan seperti terlihat pada tabel 4 . 
Tabel 1. Hasil Pengujian Blackbox Testing

\begin{tabular}{|c|c|c|}
\hline Komponen & Skenario & Hasil \\
\hline Halaman Utama & Menampilkan bukupada halaman utama website & Blackbox \\
\hline Halaman Login & Isi User name dan password & Blackbox \\
\hline Halaman Buku Tamu & $\begin{array}{l}\text { Isi nama, No Whatsaap, Kelas, Menampilkan tanggal } \\
\text { kunjungan }\end{array}$ & Blackbox \\
\hline Halaman Detail Buku & $\begin{array}{l}\text { Menampilkan judul, kategori, pengarang, tahun, edisi, } \\
\text { penerbit, rak, status, synopsis }\end{array}$ & Blackbox \\
\hline Halaman Dasboard & Menampilkan total buku,tamu, peminjaman & Blackbox \\
\hline Halaman tamu & $\begin{array}{l}\text { Menampilkan data tamu, tombol tambah, edit, hapus, } \\
\text { pagination, cari }\end{array}$ & Blackbox \\
\hline Halaman buku & $\begin{array}{l}\text { Menampilkan data buku, tombo tambah, edit, hapus, cari, } \\
\text { dan tombol barcode. }\end{array}$ & Blacbox \\
\hline Halaman Kategori & $\begin{array}{l}\text { Menampilkan data kategori buku, tombol tambah, edit, } \\
\text { hapus, dan cari }\end{array}$ & Blackbox \\
\hline Halaman Pengarang & $\begin{array}{l}\text { Menampilkan pengarang, tombol tambah, edit, hapus, dan } \\
\text { cari }\end{array}$ & Blackbox \\
\hline Halaman Rak & $\begin{array}{l}\text { Menampilkan rak buku, tombol tambah, edit, hapus, dan } \\
\text { tombol cari }\end{array}$ & Blackbox \\
\hline $\begin{array}{l}\text { Halaman } \\
\text { Peminjaman }\end{array}$ & $\begin{array}{l}\text { Menampilkan data peminjaman buku tombol tambah, edit, } \\
\text { hapus, dan cari }\end{array}$ & Blackbox \\
\hline $\begin{array}{l}\text { Halaman } \\
\text { notifikasi }\end{array}$ & $\begin{array}{l}\text { Menampilkan List Peminjman, dan Tombol Kirim Notif, } \\
\text { setting pesan }\end{array}$ & Blackbox \\
\hline $\begin{array}{l}\text { Halaman Setting Web } \\
\text { Aplikasi }\end{array}$ & $\begin{array}{l}\text { Dapat Mengubah Logo, Nama website, alamat, deskripsi, dan } \\
\text { tema }\end{array}$ & Blackbox \\
\hline Logout & Menampilkan pesan validasi Logout & Blackbox \\
\hline
\end{tabular}

Tabel 2. Skala Likert

\begin{tabular}{lc}
\hline \multicolumn{1}{c}{ Jawaban } & Skor \\
\hline SS = Sangat Setuju & 5 \\
S = Setuju & 4 \\
KS = Kurang Setuju & 3 \\
TS = Tidak Setuju & 2 \\
STS= Sangat Tidak & 1 \\
Setuju & \\
\hline
\end{tabular}

Tabel 3. Kuisioner

\begin{tabular}{cl}
\hline No & \multicolumn{1}{c}{ Pertanyan } \\
\hline 1 & $\begin{array}{l}\text { Apakah aplikasi smart library bebasis web SMP Negeri } 2 \text { cisaat ini memberikan kemudahan } \\
\text { dalam melakukan peminjaman buku? }\end{array}$ \\
2 & $\begin{array}{l}\text { Apakah aplikasi smart library berbasis web pada SMP Negeri } 2 \text { cisaat ini memberi } \\
\text { kemudahan keika mencari buku yang di inginkan? }\end{array}$ \\
3 & $\begin{array}{l}\text { Apakah aplikasi smart library bebasis web SMP Negeri } 2 \text { cisaat ini memberikan kemudahan } \\
\text { ketika melakukan perpanjangan peminjaman buku? }\end{array}$ \\
4 & $\begin{array}{l}\text { Apakah aplikasi smart library bebasis web SMP Negeri } 2 \text { cisaat ini memberikan kemudahan } \\
\text { ketika melihat katalog buku perpustakaan? }\end{array}$ \\
5 & $\begin{array}{l}\text { Apakah aplikasi smart library bebasis web SMP Negeri } 2 \text { cisaat ini dapat meningkatkan } \\
\text { kualitas pelayanan petugas perpustakaan? } \\
\text { keterlambatan peminjaman? }\end{array}$ \\
& $\begin{array}{l}\text { Apakah aplikasi smart library bebasis web SMP Negeri } 2 \text { cisaat ini dapat dipelajari dengan } \\
\text { mudah? }\end{array}$
\end{tabular}


Tabel 4. Kuisioner Pertanyaan 1

\begin{tabular}{lccccc}
\hline \multicolumn{1}{c}{ Ket. Jawaban } & Skor & Frek & Total Skor & Nilai Presentase & Kep \\
\hline Sangat Setuju & 5 & 6 & 30 & & \\
Setuju & 4 & 24 & 96 & $(126 /(30 * 5)) * 100=84 \%$ & SETUJU \\
Kurang Setuju & 3 & 0 & 0 & & \\
Tidak Setuju & 2 & 0 & 0 & \\
Sangat Tidak Setuju & 1 & 0 & 0 & & \\
\hline \multicolumn{1}{c}{ Jumlah } & & 30 & 126 & & \\
\hline
\end{tabular}

Tabel 5. Kuisioner Pertanyaan 2

\begin{tabular}{lccccc}
\hline \multicolumn{1}{c}{ Ket. Jawaban } & Skor & Frek & Total Skor & Nilai Presentase & Kep \\
\hline Sangat Setuju & 5 & 6 & 15 & & \\
Setuju & 4 & 24 & 10 & & \\
Kurang Setuju & 3 & 0 & 5 & & \\
Tidak Setuju & 2 & 0 & 0 & $(130 /(30 * 5))^{*} 100=86,7 \%$ & SANGAT \\
Sangat Tidak Setuju & 1 & 0 & 0 & & SETUJU \\
\hline \multicolumn{1}{c}{ Jumlah } & & 30 & 130 & & \\
\hline
\end{tabular}

Tabel 6. Kuisioner Pertanyaan 3

\begin{tabular}{lccccc}
\hline \multicolumn{1}{c}{ Ket. Jawaban } & Skor & Frek & Total Skor & Nilai Presentase & Kep \\
\hline Sangat Setuju & 5 & 10 & 50 & & \\
Setuju & 4 & 15 & 60 & & \\
Kurang Setuju & 3 & 4 & 12 & & \\
Tidak Setuju & 2 & 1 & 2 & $(124 /(30 * 5))^{*} 100=82,67 \%$ & SETUJU \\
Sangat Tidak Setuju & 1 & 0 & 0 & & \\
\hline \multicolumn{1}{c}{ Jumlah } & & 30 & 124 & & \\
\hline
\end{tabular}

Tabel 7. Kuisioner Pertanyaan 4

\begin{tabular}{lccccc}
\hline \multicolumn{1}{c}{ Ket. Jawaban } & Skor & Frek & Total Skor & Nilai Presentase & Kep \\
\hline Sangat Setuju & 5 & 10 & 50 & & \\
Setuju & 4 & 15 & 60 & & \\
Kurang Setuju & 3 & 5 & 15 & & \\
Tidak Setuju & 2 & 0 & 0 & $(125 /(30 * 5))^{*} 100=83,3 \%$ & SETUJU \\
Sangat Tidak Setuju & 1 & 0 & 0 & & \\
\hline \multicolumn{1}{c}{ Jumlah } & & 30 & 125 & & \\
\hline
\end{tabular}

Tabel 8. Kuisioner Pertanyaan 5

\begin{tabular}{lccccc}
\hline \multicolumn{1}{c}{ Ket. Jawaban } & Skor & Frek & Total Skor & Nilai Presentase & Kep \\
\hline Sangat Setuju & 5 & 3 & 15 & & \\
Setuju & 4 & 24 & 96 & & \\
Kurang Setuju & 3 & 3 & 9 & & \\
Tidak Setuju & 2 & 0 & 0 & $(120 /(30 * 5))^{*} 100=86,7 \%$ & SETUJU \\
Sangat Tidak Setuju & 1 & 0 & 0 & & \\
\hline \multicolumn{1}{c}{ Jumlah } & & 30 & 120 & & \\
\hline
\end{tabular}

Tabel 9. Kuisioner Pertanyaan 6

\begin{tabular}{lccccc}
\hline \multicolumn{1}{c}{ Ket. Jawaban } & Skor & Frek & Total Skor & Nilai Presentase & Kep \\
\hline Sangat Setuju & 5 & 2 & 10 & & \\
Setuju & 4 & 23 & 92 & & \\
Kurang Setuju & 3 & 5 & 15 & & \\
Tidak Setuju & 2 & 0 & 0 & $\left(117 /\left(30^{*} 5\right)\right)^{*} 100=86,7 \%$ & SETUJU \\
Sangat Tidak Setuju & 1 & 0 & 0 & & \\
\hline \multicolumn{1}{c}{ Jumlah } & & 30 & 117 & & \\
\hline
\end{tabular}


Tabel 10. Kuisioner Pertanyaan 7

\begin{tabular}{lccccc}
\hline \multicolumn{1}{c}{ Ket. Jawaban } & Skor & Frek & Total Skor & Nilai Presentase & Kep \\
\hline Sangat Setuju & 5 & 3 & 15 & & \\
Setuju & 4 & 23 & 92 & & \\
Kurang Setuju & 3 & 4 & 12 & & \\
Tidak Setuju & 2 & 0 & 0 & $(119 /(30 * 5)) * 100=86,7 \%$ & SETUJU \\
Sangat Tidak Setuju & 1 & 0 & 0 & & \\
\hline \multicolumn{1}{c}{ Jumlah } & & 30 & 119 & & \\
\hline
\end{tabular}



Gambar 18. Diagram Frekuensi Jawaban 1



Gambar 19. Diagram Frekuensi Jawaban 2



Gambar 20. Diagram Frekuensi Jawaban 3



Gambar 21. Diagram Frekuensi Jawaban 4



Gambar 22. Diagram Frekuensi Jawaban 5



Gambar 23. Diagram Frekuensi Jawaban 6



Gambar 24. Diagram Frekuensi Jawaban 7

\section{KESIMPULAN}

Setelah melakukan tahap analisis, perancangan, implementasi dan pengujian maka dapat diperoleh kesimpulan antara lain Aplikasi ini sudah dapat mempermudahkan petugas perpustakaan dalam mengelola perpustaakan menjadi sistematis dan efisien, sehingga memperingan pekerjaan mereka. Kemudian dengan dibangunnya aplikasi smart library untuk 
petugas perpustakaan dalam peminjaman dapat mengurangi antrian peminjaman dan meminimalisir kesalahan input data peminjman,karna dengan adanya aplikasi pemindaian qrcode oleh petugas pendaftaran peminjaman akan dilakukan dengan otomatis terdaftar. Dan dari hasil pengujian blackbox semua fungsionalitas sistem berfungsi dengan baik. Sedangkan Pengujian Beta menunjukan rata-rata dari hasil jawaban kuisioner adalah setuju pada aplikasi smart library yang dibangun.

\section{REFERENSI}

Alnajjar, Ahmad Y., Selvakumar Manickam, Mohammed Anbar, Samer Al-Saleem, and Omar Elejla. 2016. "TrustQR: A New Technique for the Detection of Phishing Attacks on QR Code." Advanced Science Letters.

Braude, Eric. 2017. “Incremental UML for Agile Development: Embedding UML Class Models in Source Code." in Proceedings 2017 IEEE/ACM 3rd International Workshop on Rapid Continuous Software Engineering, RCOSE 2017.

Dalpiaz, Fabiano, and Sjaak Brinkkemper. 2018. "Agile Requirements Engineering with User Stories." in Proceedings - 2018 IEEE 26th International Requirements Engineering Conference, RE 2018.

Industri, Fakultas Rekayasa, Izharyan Iqbal, R. Wahjoe Witjaksono, and M. Teguh Kurniawan. 2015. "Perancangan Aplikasi Penjualan Berbasis Web Dengan Metode Prototyping Pada CV Khatulistiwa." EProceedings of Engineering 2(1):1083-97.

Julika, Sari, and Diana Setiyawati. 2019. "Sistem Informasi Angket Pengukuran Skala Kebutuhan Materi Pembelajaran Tambahan Sebagai Pendukung Pengambilan Keputusan Di Sekolah Menengah Atas Menggunakan Skala Likert." Gadjah Mada Journal of Psychology (GamaJoP) 5(1):50.
Rachman, Dhenny, Moh Noor, Al Azam, and Benediktus Anindito. 2017. "Sistem Pemantau \& Pengendalian Rumah Cerdas." Jurnal Link 26(1):1-6.

Rosi Subhiyakto, Egia, and Danang Wahyu Utomo. 2017. “Analisis Dan Perancangan Aplikasi Pemodelan Kebutuhan Perangkat Lunak Menggunakan Metode Prototyping." Prosiding Seminar Nasional Multi Disiplin IImu \& Call For Papers UNISBANK Ke3(SENDI_U 3) 2017 (207):57-62.

Saleh, Abdul Rahman, and Rita Komalasari. 2014. "Pengertian Perpustakaan Dan DasarDasar Manajemen Perpustakaan." Manajemen Perpustakaan.

Satoto, Kodrat Iman, Kurniawan Teguh Martono, R. Rizal Isnanto, and Rinta Kridalukmana. 2016. “Design of Management Information Systems Research, Publications and Community Service." in ICITACEE 2015 2nd International Conference on Information Technology, Computer, and Electrical Engineering: Green Technology Strengthening in Information Technology, Electrical and Computer Engineering Implementation, Proceedings.

Titan, Titan, Devyano Luhukay, and Yohannes Kurniawan. 2014. "Analisis Dan Perancangan Sistem Informasi Perpustakaan Sma Negeri Xyz." ComTech: Computer, Mathematics and Engineering Applications 5(1):387.

Westerkamp, Martin, Sebastian Gondor, and Axel Kupper. 2019. "Tawki: Towards SelfSovereign Social Communication." in Proceedings - 2019 IEEE International Conference on Decentralized Applications and Infrastructures, DAPPCON 2019. 